ORIGINAL ARTICLE

\title{
The role of job strain on return to work after carpal tunnel surgery
}

\author{
D Gimeno, B C Amick III, R V Habeck, J Ossmann, J N Katz
}

Occup Environ Med 2005;62:778-785. doi: 10.1136/oem.2004.016931

See end of article for authors' affiliations

.....................

Correspondence to:

Dr D Gimeno, Southwest Center for Occupational and Environmental Health,

The University of Texas

School of Public Health,

Health Science Center at

Houston, 1200 Herman

Pressler Street, RAS

W1004D, PO Box 20186,

Houston, Texas 77225-

0186 USA; David.

Gimeno.1@uth.tmc.edu

Accepted 26 May 2005

\begin{abstract}
Aims: To examine the impact of job strain (that is, high psychological job demands and low job control) on return to work and work role functioning at two months, six months, or both, following carpal tunnel release surgery.

Methods: A community based cohort of carpal tunnel syndrome (CTS) patients from physician practices was recruited between April 1997 and October 1998 throughout Maine (USA). 128 patients at two months and 122 at six months completed all relevant questions. A three level outcome variable indicated whether patients had: (1) returned to work functioning successfully, (2) returned to work functioning with limitations, or (3) not returned to work for health reasons. Two job strain measures were created: one, by combining psychological job demands and job control; and two, by dividing demands by control. Ordinal logistic regression was used to identify predictors of the three level work outcome variable.

Results: After adjustment, workers with high demands and high control (active work) were less likely to successfully return to work $(O R=0.22 ; p=0.014)$ at two months. Having a job with higher demands than job control (high strain) predicted not returning to work or returning to work but not successfully meeting job demands $(\mathrm{OR}=0.14 ; \mathrm{p}=0.001)$, at six months.

Conclusions: The findings underscore the role of psychosocial work conditions, as defined by the Karasek demand-control model, in explaining a worker's return to work. Clinicians, researchers, and employers should consider a multidimensional and integrative model of successful work role functioning upon return to work. Moreover, since the evidence of the effects of work process changes on the reduction of CTS is very scarce, these findings point to the opportunity for collaborative workplace interventions to facilitate successful return to work.
\end{abstract}

C arpal tunnel syndrome (CTS), an entrapment neuropathy of the median nerve in the wrist, is one of the most prevalent upper extremity musculoskeletal conditions. ${ }^{12}$ The median nerve passes into the hand through the carpal tunnel, which is bound anteriorly by the tough carpal ligament and posteriorly by the carpal bone. Along with the median nerve, nine flexor tendons of the fingers traverse the carpal canal. These tendons can become thickened from inflammation and other processes. The thickened tendons can compress the median nerve, giving rise to symptoms of nerve irritation. These symptoms usually start gradually and include pain, weakness, burning, tingling, or numbness in the fingers, occasionally also involving the palm and rarely radiating up the arm. Symptoms may make it difficult to perform manual tasks, such as forming a fist or grasping small objects. ${ }^{3}$

Medical costs related to CTS exceed \$1 billion per year with over 250000 carpal tunnel release surgical procedures performed annually in the USA. ${ }^{4}$ Because it has been estimated that $50 \%$ of all CTS cases may be work related, CTS and carpal tunnel release surgery may have considerable impact on work productivity. Non-surgical treatments such as local corticosteroid injection, ${ }^{5}$ oral steroids, splinting, ultrasound, yoga, and carpal bone mobilisation ${ }^{6}$ have shown short term benefits (2-8 weeks). However, surgery tends to provide the most reliable and lasting relief in people with moderate to severe symptoms. ${ }^{7}$ Compared with other treatment modalities, carpal tunnel release surgery is associated with an earlier return to work and symptom reduction is expected in $70-90 \%$ of all carpal tunnel release cases. ${ }^{2-11}$ The worker's compensation costs associated with CTS are higher than those associated with other musculoskeletal injuries ${ }^{12}$ as reflected in longer duration away from work and higher medical costs. The rising number of service sector jobs typically involving upper extremity-intensive tasks may increase the number of workers at high risk of developing CTS, and thus, incidence and costs may increase. ${ }^{13} 14$

In order to design workplace interventions that reduce CTS related work disability, the full range of factors involved in the return to work process must be identified..$^{15-17}$ The return to work literature has identified a broad range of clinical, personal, economic, legal, and work related factors important in reducing CTS related work disability. ${ }^{18-22}$ Prospective studies considering CTS specific populations have similarly found clinical, economic, legal, psychosocial, work related physical demands and organisational policies and practices critical in reducing work absence, time until return to work, and improved work role functioning. ${ }^{23-26}$ Despite their recognised importance in predicting a range of health outcomes, ${ }^{27}$ fewer studies have considered psychosocial work conditions among CTS workers.

The Karasek demand-control model is a widely used paradigm for conceptualising and measuring psychosocial work stress factors relevant to the design of workplace based interventions. ${ }^{28}$ Psychosocial job demands, job control, and their combination have been associated with sickness absence, ${ }^{29-31}$ however, only limited cross sectional ${ }^{32} 33$ and

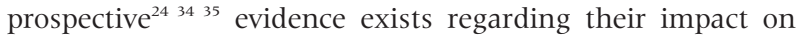
return to work. The populations investigated were long term sick listed employees, ${ }^{34}$ workers with low back injury, ${ }^{33}{ }^{35}$ and only three were conducted among workers with CTS. ${ }^{24} 2532$ One investigated the combination of high psychological job demands and low job control on work status changes following CTS diagnosis. ${ }^{24}$ The other two examined the

Abbreviations: CTS, carpal tunnel syndrome; JCQ, Job Content Questionnaire 
independent effects of high psychosocial job demands and low job control on return to work among workers undergoing carpal tunnel release surgery, one retrospectively ${ }^{32}$ and one prospectively. ${ }^{25}$ Further, studies indicate that it is often erroneously assumed that returning to work implies successful work role functioning. ${ }^{36}{ }^{37}$ Except for one case, ${ }^{25}$ outcomes in the studies examining the role of the demand-control model did not consider worker's functional status upon returning to work. ${ }^{16} 38$

The only previous study examining work role functioning upon returning to work after CTS surgery was conducted using the same cohort as the present study. ${ }^{25}$ Psychosocial job demands and job control were explored separately and no significant effects were found. The present work extends the earlier work with the same cohort by explicitly testing the combined effect of the psychosocial job demands and job control as specified by the Karasek demand-control model. The present study hypothesises that, adjusted for potential confounders, the combination of negative psychosocial job demands and job control reduce the likelihood of return to work or functioning successfully in the work role upon return to work at two months, six months, or both, following carpal tunnel release surgery.

\section{METHODS}

\section{Participants and study sample}

A community based study was conducted in Maine to recruit CTS patients from 15 physician practices who performed carpal tunnel release (orthopaedics, plastic surgery, and neurosurgery). Patient eligibility criteria included: physician diagnostic impression of CTS, symptoms of numbness or tingling in at least two of the first four fingers for at least one month, confirmed diagnosis with nerve conduction testing, having been scheduled for carpal tunnel release, and working at least 20 hours per week at the time symptoms developed. Patients aged under 18 years old, with previous carpal tunnel release surgery, pregnant, retired, or full time students were excluded. Both the Brigham and Women's Hospital and the University of Texas Health Science Center Institutional Review Boards approved the study protocol.

Eligible patients $(n=241)$ were approached and recruited consecutively by participating practices between April 1997 and October 1998. In the present study, questionnaires were mailed to consenting patients before and two, six, and 12 months after undergoing carpal tunnel release surgery. After seven patients refused to participate, 234 patients were sent baseline questionnaires and 197 patients (84\%) returned them. Among these, 181 (92\%) returned at least one follow up questionnaire: $168(85 \%)$ returned questionnaires at two months, $158(80 \%)$ at six months, and $157(80 \%)$ at 12 months, and $136(69 \%)$ returned all follow up questionnaires. In the present study, completed work role functioning data at baseline and two or six months after surgery were required. Only $128(65 \%)$ patients at two months and $122(62 \%)$ at six months fulfilled this requirement. Incomplete data at 12 months precluded meaningful analyses at this period.

The proportion of potentially eligible patients referred to the Maine Coordinating Center is difficult to estimate. A similarly designed earlier study in Maine showed the sample to be representative of all eligible patients in all the physician practices with respect to age, sex, work status, workers' compensation status, and satisfaction with surgery 18 months postoperatively. ${ }^{4}$

As data were dropped before analysis, comparisons between the full sample (that is, the 197 workers) and the reduced sample (that is, those who returned at least one follow up questionnaire) and the two analytic samples at two and six months were performed. Among the full sample the average age was 46 (SD 10) years, most patients were females $(57 \%)$, white race $(98 \%)$, and had high school or less education $(61 \%)$. This compares favourably with the reduced sample where the average age was 46 (SD 9), most were females $(58 \%)$, white race $(97 \%)$, and had high school or less education $(59 \%)$. The analytic samples had similar distributions. Missing data in the full sample precluded further comparisons. Comparisons between the reduced and the analytic samples showed overall agreement for the following variables: age, sex, race, marital status, educational level, occupation, hand and wrist symptom severity, bilateral carpal tunnel symptoms, physical health status, musculoskeletal pain sites, depression, self-efficacy, workers' compensation claims, physical and psychological job demands, job control, family and job social support, and organisational policies and practices. In the reduced sample there was a slightly greater proportion of obese $(\mathrm{BMI} \geqslant 30)$ workers $(47 \%)$ than the analytic samples (both about $40 \%$ ). A table showing the comparisons is available from the first author.

Because patients were recruited through physician practices, a selection effect could have been present. Although the small sample limited analyses of physician practices as a random effect, no significant variability between patients from different physician practices was found in another analysis of the cohort where work absence was the outcome. ${ }^{26}$

\section{Work role functioning}

Patients confirmed whether they were working or not at each time point (baseline and two and six months post surgery). Patients who returned to work after two or six months following carpal tunnel surgery were asked to complete a subset of 15 questions derived from a 26 item measure of work role functioning. ${ }^{38}$ Because of the length and complexity of the questionnaire and the desire to measure work limitations at multiple time points, the researchers shortened the instrument following two criteria. First, conceptually, surgery was expected to primarily impact the physical and output demands' subscales of work role functioning. Given the desire to have a work role functioning measure responsive to change, more items from these subscales were selected. Second, items with the highest item-to-scale correlation and those that when dropped would significantly reduce the scales' internal consistency were selected. The final 15 items selected $(\alpha=0.91)$ represented five work demands dimensions associated with doing the work: two of the four WL-26 original items for psychological/cognitive, four of eight from physical, all three from social, two of six from work scheduling, and four of five output demands (box l).

For each statement, patients rated the percentage of time experiencing problems meeting the work demands as a result of their physical and emotional health during the previous week. ${ }^{25}$ As the questionnaire was designed for all workers, some work demands may not be relevant in a respondent's job. To reduce burden, the respondent could correctly endorse "does not apply to my job" when answering the work role functioning questions. As part of the scale construction, "does not apply to my job" responses were reviewed to see if there was a significant endorsement of any one item; there was not. In fact, numbers were very small, with $1-2 \%$ of "does not apply to my job" endorsement for any given work demand. This small percentage was rescored to missing. It was specified that if more than $20 \%$ of the items were missing the score was set to missing; there were no such cases in the sample.

Item response options ranged from $1(0 \%$ of the time having problems meeting job demands) to $5(100 \%$ of the time having problems meeting demands). To obtain scores of 


\section{Box 1: Work role functioning measure}

Physical demands

- Lift, carry, or move objects at work

- Keep your body in one position longer than 30 minutes at a time

- Bend, twist, or reach

- Use hand operated tools or equipment (such as pen, drill, sander, keyboard, or computer mouse)

Psychological/cognitive demands

- Concentrate on your work

- Remember things having to do with your work

- Scheduling

- Stick to your work routine or schedule

- Do your work without needing frequents rests or breaks

Social demands

- Talk with people in person, in meetings, or on the phone

- Control irritability or anger toward people

- Help other people get work done

Output demands

- Do your work without making mistakes

- Satisfy those people who judge your work

- Feel a sense of accomplishment

- Finish all your work

functioning instead of limitations, responses were re-scored to a $0-4$ scale, where 0 represented $100 \%$ of the time having problems meeting demands and 4 represented $0 \%$ of the time having problems. Then, a simple average work role functioning score was created by taking the mean response. The mean score was multiplied by 25 to create a work role functioning score that varied from 0 (difficulty meeting all 15 work demands $100 \%$ of the time) to 100 (able to meet all 15 work demands $100 \%$ of the time).

Work role functioning was not computed for patients not working due to health problems (that is, unable to function in the work role). However, because not working is the most extreme form of unsuccessful work role functioning and the six month work role functioning measure was positively skewed (mean 90; standard deviation 13; range 32-100), a three level outcome variable was created to indicate whether patients: (1) had returned to work and were functioning successfully (able to meet the job demands at least $90 \%$ of the time), (2) had returned to work but were functioning with limitations (unable to meet the job demands at least $90 \%$ of the time), or (3) had not returned to work for health reasons.

Examination of whether and when job changes occurred showed that only three patients at two months and three patients at six months changed employers. Excluding them did not significantly change results. Changes to the work situation due to CTS were reported by $54 \%$ of the patients, although a detailed description of the changes was not available. In a preliminary analysis, a variable indicating whether or not job modification occurred was introduced in the regression models but no significant effect on work role functioning was found.

\section{Psychosocial work conditions}

Psychosocial work conditions were assessed following the job strain model with a subset of Job Content Questionnaire
(JCQ) items ${ }^{39} 40$ (box 2). Given the questionnaire length and complexity and the goal to have multiple time point measurements, the standard 14-item JCQ measure (that is, five items for job psychological demands and nine for job control) was shortened following practical selection criteria. Items with the highest item-to-scale correlation and those that when dropped would significantly reduce the scales' internal consistency were selected. Six items were selected from the original JCQ measure: three for job psychological demands and three for job control. Two more items were included in the job control scale. The item on "possibility to change tasks because of pain" was selected after the questionnaire was piloted in three focus groups. ${ }^{41}$ Karasek (personal communication) suggested the "time for phone call" item to be used in the knowledge economy. Therefore, the final reduced version contained three items to measure psychological job demands $(\alpha=0.72)$ and five for job control $(\alpha=0.83)$. No patients reported significant work conditions changes during the study so only baseline measures were used. Scores of psychological job demands and job control were created from summated averages of the rating scale responses that varied from 1 (strongly disagree) to 4 (strongly agree). For the analyses, job demands and job control were dichotomised by their medians, indicating low and high levels for both demands and control. Values equal to the median were classified into the less hazardous exposure level (that is, low demands or high control, respectively).

According to the job strain model, ${ }^{42}$ four work states (the Karasek quadrants) were created by cross classifying the dichotomous variables of psychological job demands and job control: high strain (high demands and low control), active (high demands and high control), passive (low demands and low control), and low strain (low demands and high control). In the analyses, low strain served as the reference group. Two main hypotheses were stated..$^{42}$ First, the job strain hypothesis states that the most adverse health reactions as well as reduced feelings of mastery and coping effectiveness will occur in a high strain work state compared to a low strain work state. Second, the active learning hypothesis states that learning and psychological growth as well as improved mastery feelings and coping strategies will arise in an active work state compared to a passive work state.

Additionally, to overcome potential problems with bivariate splits potentially leading to type I errors, ${ }^{43}$ a second method for classifying job strain was used. A continuous job strain measure was created dividing psychological job demands by job control. ${ }^{44}{ }^{45}$ Named after the demand-control model's job strain hypothesis, the job strain quotient distribution was split into quartiles with the bottom quartile

\section{Box 2: Psychosocial work conditions measure}

Psychological job demands

- Job is very hectic

- Job requires working very hard

- Asked to do an excessive amount of work

Job control

- Get to do a variety of different things on my job

- Have a lot of freedom to decide how I do my work

- Have a lot of say about what happens on my job

- Can do other tasks instead if a particular work task is painful or uncomfortable

- Can make a personal telephone call during the work day 


\begin{tabular}{|c|c|c|c|c|c|c|c|c|c|c|c|c|}
\hline \multirow[b]{3}{*}{ Variable } & \multicolumn{6}{|c|}{ Two months } & \multicolumn{6}{|c|}{ Six months } \\
\hline & \multicolumn{2}{|c|}{ Not working } & \multicolumn{2}{|c|}{$\begin{array}{l}\text { Working with } \\
\text { limitations }\end{array}$} & \multicolumn{2}{|c|}{$\begin{array}{l}\text { Working } \\
\text { successfully }\end{array}$} & \multicolumn{2}{|c|}{ Not working } & \multicolumn{2}{|c|}{$\begin{array}{l}\text { Working with } \\
\text { limitations }\end{array}$} & \multicolumn{2}{|c|}{ Working successfully } \\
\hline & $n$ & $(\%)$ & $n$ & $(\%)$ & n & $(\%)$ & $n$ & $(\%)$ & $n$ & $(\%)$ & $n$ & (\%) \\
\hline \multicolumn{13}{|c|}{ Psychological job demands } \\
\hline Low & 19 & $(26.8)$ & 21 & $(29.6)$ & 31 & (43.7) & 10 & (15.9) & 16 & (25.4) & 37 & $(58.7)$ \\
\hline High & 20 & (35.7) & 15 & $(26.8)$ & 21 & (37.5) & 9 & (15.5) & 16 & (27.6) & 33 & $(56.9)$ \\
\hline \multicolumn{13}{|l|}{ Job control } \\
\hline High & 20 & $(25.0)$ & 23 & $(28.8)$ & 37 & $(46.3)$ & 4 & $(5.7)$ & 16 & (22.9) & 50 & $(71.4)$ \\
\hline Low & 19 & (39.6) & 13 & (27.1) & 16 & (33.3) & 15 & $(28.8)$ & 16 & (30.8) & 21 & $(40.4)$ \\
\hline \multicolumn{13}{|l|}{ Karasek quadrants } \\
\hline Low strain & 10 & (21.7) & 12 & (26.1) & 24 & (52.2) & 3 & (7.9) & 11 & $(28.9)$ & 24 & (63.2) \\
\hline Passive & 9 & (36.0) & 9 & (36.0) & 7 & (28.0) & 7 & (28.0) & 5 & (20.0) & 13 & (52.0) \\
\hline Active & 10 & (30.3) & 11 & (33.3) & 12 & (36.4) & 1 & (3.2) & 5 & (16.1) & 25 & $(80.6)$ \\
\hline High strain & 10 & $(43.5)$ & 4 & (17.4) & 9 & (39.1) & 8 & (29.6) & 11 & $(40.7)$ & 8 & $(29.6)$ \\
\hline \multicolumn{13}{|l|}{ Job strain quotient } \\
\hline 1 st to 3 rd quartile & 30 & (28.3) & 31 & (29.2) & 45 & (42.5) & 9 & (9.5) & 25 & (26.3) & 61 & (64.2) \\
\hline 4 th quartile & 9 & (42.9) & 5 & (23.8) & 7 & (33.3) & 10 & (38.5) & 7 & (26.9) & 9 & $(34.6)$ \\
\hline \multicolumn{13}{|l|}{ Active learning quotient } \\
\hline 1 st to 3 rd quartile & 31 & (33.0) & 28 & (29.8) & 35 & (37.2) & 17 & (18.7) & 28 & $(30.8)$ & 46 & (50.5) \\
\hline 4 th quartile & 8 & (24.2) & 8 & (24.2) & 17 & (51.5) & 2 & (6.7) & 4 & (13.3) & 24 & $(80.0)$ \\
\hline Total $^{*}$ & 39 & (30.5) & 36 & $(28.1)$ & 53 & (41.4) & 19 & (15.6) & 32 & (26.2) & 71 & (58.2) \\
\hline
\end{tabular}

*Sum across row rather than column.

indicating fewer demands and more control (low strain) and the top quartile indicating more demands and less control (high strain). This calculation does not allow creating simultaneously the four theoretically predicted work states. To redress this limitation a second quotient was similarly computed with a re-scored control scale so the higher the score the lower the control. The bottom of the distribution indicated fewer demands and less control (passive) and the top more demands and more control (active). This new quotient was named the active learning quotient after the active learning hypothesis of the demand-control model. For the regression models the three lowest quartiles were grouped. Additionally, to allow comparisons with the active learning quotient, passive work was set as the reference group in the logistic models using the quadrants.

\section{Potential covariates}

Covariates of successful work role functioning were included based on prior analyses of the relative impact of clinical, worker, family, economic/legal, job, and organisational factors on successful return to work. ${ }^{25}$ At two months, selected covariates were: work role functioning before CTS surgery (that is, at baseline), depression at baseline (measured by the SF-36 MHI-5 scale), ${ }^{46}$ and having workers' compensation claim due to CTS. Covariates at six months post surgery were baseline work role functioning, baseline self efficacy (measuring patients' confidence in managing symptoms and maintaining activities) ${ }^{47}$ self efficacy change, and organisational support (measuring organisational policies and practices relevant for worker health and safety). Detailed covariates selection procedures are reported elsewhere. $^{25}$

\section{Statistical analysis}

The analysis strategy included the following steps. Firstly, the distribution of the psychosocial work exposures across levels of successful return to work was calculated. Secondly, ordinal logistic regression models with robust estimation procedures for the standard error were employed to estimate unadjusted odds ratios (OR) and $95 \%$ confidence limits ${ }^{48}$ of the associations between psychosocial work exposures and return to work. Tests of the non-proportionality of the odds supported the appropriateness of ordinal logistic regression. ${ }^{49}$
Thirdly, following Hosmer and Lemeshow, ${ }^{50}$ if the OR was significant $(\mathrm{p}<0.25)$, the psychosocial work exposure was entered in multivariate ordinal logistic regression analyses together with the selected covariates. Separate models were developed for the two individual psychosocial work exposures and the four combined exposure measures. Two quadrant models were estimated: one with low strain as the reference group and one with passive as the reference group. Two quotient models were also estimated: the job strain and the active learning quotients. The analyses were conducted independently for the two and six months samples. The fit of the models was examined with the McKelvey and Zavonia's $\mathrm{R}^{2},{ }^{51}$ which varied between 0.42 and 0.61. Analyses were performed with STATA/SE version 8.2. ${ }^{52}$

\section{RESULTS}

\section{Two month results}

At two months, $70 \%(\mathrm{n}=89)$ of the sample was working and $41 \%(n=53)$ was successfully functioning in their jobs (table 1). The average work role functioning score for those working with limitations was 76.8 (SD 13.5) while, for those working successfully, work role functioning was 96.4 (SD 3.2). A greater proportion of workers who had high psychological job demands (36\%) and low job control $(40 \%)$ did not return to work, while the inverse was found for workers returning to work. Using the Karasek quadrants, workers in low strain jobs were more frequently working successfully $(52 \%)$, whereas workers in high strain jobs were more frequently not working $(44 \%)$. The job strain quotient showed similar results with $43 \%$ in high strain not working. Workers in passive jobs were as likely to not work as work with limitations (36\%), with fewer (28\%) working successfully. The proportion of workers in active jobs increased across the work role functioning groups: $30 \%$ not working, $33 \%$ working with limitations, and 36\% successfully working and this trend was more obvious using the active learning quotient $(24 \%, 24 \%$, and $52 \%$, respectively).

Separate logistic regression results for each psychosocial work factor or job strain measure and return to work are shown in table 2. For the Karasek quadrants, the likelihood of returning to work after adjustment was lower for workers with active jobs compared to both workers in low strain jobs $(\mathrm{OR}=0.22 ; 95 \% \mathrm{CI} 0.09$ to 0.59$)$ and passive jobs $(\mathrm{OR}=0.22$; 
Table 2 Relation between psychosocial work factors and return to work at two $(n=128)$ and six $(n=122)$ months after carpal tunnel release surgery

\begin{tabular}{|c|c|c|c|c|c|c|c|c|c|c|c|c|}
\hline \multirow[b]{2}{*}{ Variable } & \multicolumn{6}{|c|}{ Two months } & \multicolumn{6}{|c|}{ Six months } \\
\hline & ORc & $95 \% \mathrm{Cl}$ & $\begin{array}{l}\text { p value } \\
<0.25^{*}\end{array}$ & ORat & $95 \% \mathrm{Cl}$ & $\begin{array}{l}\mathbf{p} \text { value } \\
<\mathbf{0 . 0 5}\end{array}$ & ORc & $95 \% \mathrm{Cl}$ & $\begin{array}{l}\text { p value } \\
<0.25^{*}\end{array}$ & ORał & $95 \% \mathrm{Cl}$ & $\begin{array}{l}\text { P value } \\
<0.05\end{array}$ \\
\hline \multicolumn{13}{|l|}{$\begin{array}{l}\text { Psychological job } \\
\text { demands§ }\end{array}$} \\
\hline Low & 1 & & & & & & 1 & & & & & \\
\hline High & 0.72 & $0.37-1.39$ & 0.327 & & & & 0.95 & $0.41-1.91$ & 0.881 & & & \\
\hline \multicolumn{13}{|l|}{ Job control§ } \\
\hline High & 1 & & & 1 & & & 1 & & & 1 & & \\
\hline Low & 0.55 & $0.28-1.07$ & 0.079 & 1.87 & $0.76-4.58$ & 0.174 & 0.24 & $0.12-0.50$ & $<0.005$ & 0.64 & $0.23-1.75$ & 0.381 \\
\hline \multicolumn{13}{|l|}{ Karasek quadrants (I) } \\
\hline Low strain & 1 & & & 1 & & & 1 & & & 1 & & \\
\hline Passive & 0.43 & $0.18-1.01$ & 0.052 & 1.03 & $0.36-2.95$ & 0.952 & 0.48 & $0.16-1.43$ & 0.190 & 1.11 & $0.29-4.31$ & 0.882 \\
\hline Active & 0.57 & $0.25-1.29$ & 0.079 & 0.22 & $0.09-0.59$ & 0.003 & 2.36 & $0.81-6.88$ & 0.115 & 1.03 & $0.27-3.93$ & 0.966 \\
\hline High strain & 0.45 & $0.16-1.31$ & 0.143 & 0.93 & $0.26-3.32$ & 0.909 & 0.26 & $0.10-0.64$ & 0.003 & 0.35 & $0.09-1.49$ & 0.148 \\
\hline \multicolumn{13}{|l|}{ Job strain quotient } \\
\hline 1st to 3rd quartile & 1 & & & & & & 1 & & & 1 & & \\
\hline 4th quartile & 0.59 & $0.24-1.49$ & 0.264 & & & & 0.24 & $0.09-0.59$ & 0.002 & 0.14 & $0.04-0.43$ & 0.001 \\
\hline \multicolumn{13}{|l|}{ Karasek quadrants (II) } \\
\hline Passive & 1 & & & 1 & & & 1 & & & 1 & & \\
\hline Low strain & 2.35 & $0.99-5.58$ & 0.052 & 0.97 & $0.34-2.77$ & 0.952 & 2.07 & $0.70-6.10$ & 0.190 & 0.90 & $0.23-3.51$ & 0.882 \\
\hline High strain & 1.06 & $0.35-3.24$ & 0.913 & 0.90 & $0.23-3.55$ & 0.888 & 0.53 & $0.17-1.64$ & 0.274 & 0.32 & $0.86-1.17$ & 0.084 \\
\hline Active & 1.34 & $0.55-3.26$ & 0.513 & 0.22 & $0.65-0.74$ & 0.014 & 4.88 & $1.41-16.95$ & 0.013 & 0.93 & $0.23-3.73$ & 0.917 \\
\hline \multicolumn{13}{|c|}{ Active learning quotient } \\
\hline 1 st to 3 rd quartile & 1 & & & 1 & & & 1 & & & 1 & & \\
\hline 4th quartile & 1.70 & $0.79-3.66$ & 0.177 & 0.64 & $0.26-1.53$ & 0.313 & 3.84 & $1.42-10.36$ & 0.008 & 0.93 & $0.27-3.26$ & 0.915 \\
\hline \multicolumn{13}{|c|}{$\begin{array}{l}\text { ORc, crude odds ratio; } \mathrm{Cl} \text {, confidence interval. } \\
\text { *Exposures variables with } \mathrm{p} \text { values higher than } 0.25 \text { in the crude models are not carried forward to the adjusted models. } \\
\text { †Adjusted odds ratio for baseline work role functioning, depression and workers' compensation claimant due to carpal tunnel syndrome (see text). } \\
\text { †Adjusted odds ratio for baseline work role functioning, baseline self efficacy, improving in self efficacy, and organisational support (see text). } \\
\text { §Psychological job demands and job control are also adjusted for each other in the adjusted models. }\end{array}$} \\
\hline
\end{tabular}

95\% CI 0.65 to 0.74$)$. High strain and passive quadrants, while marginally significant in unadjusted models, become non-significant after adjustment. No effect was found for the two quotients.

Confounders at two months had significant and consistent effects across all models in table 2 (data available from the first author). Baseline work role functioning significantly predicted (ORs between 1.03 and 1.04) better work role functioning. Workers with baseline depression (ORs 0.38 to $0.51)$ were less likely to return to work and function successfully. Filing a workers' compensation claim had lower risk of successful work role functioning (ORs from 0.22 to $0.25)$.

\section{Six month results}

By six months, $84 \%(n=103)$ of the sample had returned to work, with $58 \%$ functioning successfully (table 1). The average work role functioning score for those working with limitations was 78.5 (SD 13.3) while for those working successfully was 96.1 (SD 3.5). Among patients with high demands, $16 \%$ were not working, $28 \%$ were working with limitations, and 57\% were working successfully. Among those with low job control, $29 \%$ did not return to work, $31 \%$ were working with limitations and $40 \%$ were working successfully. For workers classified as having a high strain job using the Karasek quadrants, 30\% were working successfully while, using the job strain quotient, percentages were slightly greater $(35 \%)$. For workers classified as having an active job using the Karasek quadrants, $81 \%$ were working successfully and only $3 \%$ were not working. Using the active learning quotient, percentages were slightly different: $80 \%$ and $7 \%$, respectively.

In six month logistic regression models (table 2), psychological job demands were not significantly associated with six month return to work. After adjustment, job control became non-significant $(\mathrm{OR}=0.64 ; 95 \%$ CI 0.23 to 1.75$)$. High strain classified using the Karasek quadrants was not significantly associated with return to work $(\mathrm{OR}=0.35 ; 95 \% \mathrm{CI} 0.09$ to 1.49), whereas high strain classified with the job strain quotient remained significant $(\mathrm{OR}=0.14 ; 95 \%$ CI 0.04 to 0.43 ). Using the Karasek quadrants, workers in active jobs were more likely to return to work than passive jobs $(\mathrm{OR}=4.88 ; 95 \%$ CI 1.41 to 16.95$)$. The active learning quotient showed similar results $(\mathrm{OR}=3.84 ; 95 \% \mathrm{CI} 1.42$ to 10.36). However, adjusting for either the baseline work role functioning or organisational support the active work effect diminished and became non-significant $(\mathrm{OR}=1.15$ for the Karasek quadrants and $\mathrm{OR}=1.05$ for the active quotient). Further exploration revealed most workers with active jobs ( $84 \%$ by the quadrants and $96 \%$ by the quotient) had high organisational support. Adding high baseline work role functioning $(>90)$, percentages increased only to $87 \%$ and $100 \%$, respectively.

Covariate effects were significant and consistent across all models in table 2 (data available from the first author). At six months, predictors of return to work and successful work role functioning were baseline work role functioning (ORs from 1.03 to 1.04 ), improved self efficacy (ORs from 6.78 to 9.92 ), and high organisational support (ORs from 4.41 to 4.89 ).

\section{DISCUSSION}

The present study has shown, after confounder adjustments, psychosocial work conditions were associated with return to work following carpal tunnel release surgery and functioning successfully after returning to work. In the short term (at two months), workers in active jobs (high psychological demands combined with high job control) were less likely to return to work and perform successfully than those in low strain jobs (low demands and high control). In the longer term (at six months), having a job with relatively higher psychological job demands than job control (high strain) predicted not returning to work or functioning poorly upon return. 


\section{Study limitations and strengths}

Limitations include the relatively small sample size and the moderately short follow up period. However, the present study did employ a community based sample and a prospective design, with good questionnaire response rates ( $80 \%$ for both at two and six months). The results were adjusted for a set of clinical, legal, and organisational conditions proven to be significant predictors of return to work in prior analysis. ${ }^{25}$ Among all these variables, the adjustment for baseline work role functioning makes the results particularly robust.

With regard to potential bias, three selection effects related to economics, physician practices, and analysis must be considered..$^{53}$ Firstly, some workers (that is, those unable to afford the CTS surgery) may not have been available for the recruitment. Secondly, the study sample was not population based but community based, including patients from all over Maine from a range of different physician practices. Also, all workers in the sample had surgery, a treatment preferred for people with moderate to severe symptoms ${ }^{7}$ while generally mild cases are usually given other treatments. ${ }^{5}{ }^{6}$ As stated earlier, a previous study in the same State using an analogous patient recruitment strategy generated a representative sample of all eligible patients in physician practices with respect to a broad range of variables. ${ }^{4}$ Patient selection and surgical practice may however differ across specialties. Neither a clustering (that is, the patients referred from the same physician practices) effect ${ }^{26}$ nor effect of surgery type on work related functioning was found in the present sample. ${ }^{25}$ Thirdly, completed work role functioning data were the criteria used to reduce the sample for the analyses. Response rates for the completion of the work role functioning data were only moderate $(65 \%$ at two months and $62 \%$ at six months). As a result, reducing the sample for the analyses could bias the findings. Except for fewer obese patients, the reduced samples were comparable to the full sample. Overall, the findings are unlikely to be influenced by the stated selection effects and, therefore, generalisable to nonminority workers in the USA and comparable working populations.

Following conceptual and empirical criteria, psychosocial work conditions and work role functioning measures were modified from standard measures. Modified versions were chosen to better capture the relevant features of the particular study conditions. The modified measures showed good psychometric properties and responsiveness to change, justifying their use. A potential measurement bias for the work role functioning measure has to be considered. If the "does not apply to my job" response option was chosen for some item, the item was set to missing. To compute the work role functioning score, only $20 \%$ of the work role functioning items were allowed to be missing. As there were no workers with more than $20 \%$ of missing items, the likelihood of having a measurement bias is rather limited.

The findings add to the sparse literature specifically assessing the impact of psychosocial work conditions on the return to work process. However, some differences with earlier research make comparison difficult. Two studies examined workers undergoing carpal tunnel release surgery, but no effects were found for psychological job demands and job control, which were only examined separately. One prospective study used the same cohort as the present study. ${ }^{25}$ The other was retrospective, ${ }^{32}$ but rather than measuring work role functioning as an indicator of successful return to work, the study simply measured whether a worker returned to work or not. Use of the work role functioning measure provides a more comprehensive assessment of the quality of the worker's return to work. For instance, independent of the follow up period considered, more than $25 \%$ of the sample returned to work but were unable to fulfil the required job demands without limitations.

The lack of psychological job demands and job control effects is consistent with prior findings in the same sample, ${ }^{25}$ even though the current study used different exposure cut points. Previously, only the independent effects of psychological job demands and job control but not their combined effects were explored. Therefore, the present study adds knowledge regarding the job strain model: the effects of active and high strain work on work role functioning at two and six months post CTS surgery, respectively. It contributes to a small but increasing literature on the role of job strain in secondary prevention.

\section{Psychosocial work exposures measurement}

A fundamental question in the psychosocial work research area is how to operationalise the job strain model. The use of two alternative job strain measures is unusual in the psychosocial work exposure literature. ${ }^{44}$ No previous return to work and job strain study used the quotient method. The quadrants and the quotient methods derive from the same conceptual foundation (that is, the demand and control imbalance), but both methods did not classify workers into the same work exposure states. About $72 \%$ and $67 \%$ were jointly classified as active and high strain, respectively. Although there were differences in effect size and significance irrespective of the method, all ORs were in the same direction (less than 1). This was true whether job strain or active learning effects were examined.

When cross classifying workers using the quadrant and quotient methods some ORs change direction. At two months, workers jointly classified as active with both methods were less likely to return to work $(\mathrm{OR}=0.24$; $\mathrm{p}=0.012$ ). Workers classified active only with the quotient method were more likely to return to work $(\mathrm{OR}=5.80$; $\mathrm{p}=0.044$ ), whereas workers classified active only with the quadrants method were less likely to return to work $(\mathrm{OR}=0.39 ; \mathrm{p}=0.129)$. Further examination of the group classified active only with the quotient method $(n=10)$ showed that most of them (70\%) were classified low strain with the quadrants method and that all of them had not filed a workers' compensation claim, a significant predictor of successfully returning to work at two months.

At six months, workers jointly classified as high strain were less likely to return to work $(\mathrm{OR}=0.13 ; \mathrm{p}=0.002)$. Workers classified high strain only with the quotient method were also less likely to return to work $(\mathrm{OR}=0.25 ; \mathrm{p}=0.241$ ), while workers classified high strain only with the quadrants method were more likely to return to work $(\mathrm{OR}=2.22$, $p=0.282$ ). However, the quadrant-only effect was not significant and these workers did not show differences in the six month covariates compared to other high strain workers.

In the unadjusted analyses workers in active jobs were more likely to return to work at six months than passive jobs. Once the model was adjusted for organisational support and baseline work role functioning, the relation disappeared. Further exploration revealed most workers with active jobs had both high organisational support and high baseline work role functioning. Although more research is needed, it can be preliminarily concluded that supportive organisations may create "good" jobs and functioning well at work may select workers into the "good" jobs.

Despite the limits of the sample size, these results highlight two issues important in future research. Firstly, referring to an important methodological paper, researchers contend the median split technique used in the quadrants method may cause exposure misclassification ${ }^{54}$ increasing the possibility of type I errors which the quotient method may reduce. ${ }^{43}$ If so, 


\section{Main messages}

- Work role functioning is a new measure capturing the impact of health on the ability of the worker to meet work demands and expands our assessment of the return to work process.

- The active learning quotient has been computed for the first time. This is a novel way to consider the active learning hypothesis and the potentially hazardous passive work state.

- In the short term, after carpal tunnel surgery, having a job with high job control combined with high psychological demands (active work) inhibited people from returning to work and performing successfully.

- In the longer term, having a job with relatively higher psychological job demands than job control (high strain work) predicted not returning to work or functioning poorly upon return to work.

while the high strain effect would be an actual effect, the active job effect might be spurious. As discussed above, the main findings and conclusions would not differ suggesting type I error may not be as considerable. Secondly, in cross classification there is some possible differential classification that could have risk estimation effects. Moving from differential classification to misclassification requires consensus on a reference. Alternative estimation methods such as supervisor reports and observational techniques ${ }^{55} 56$ have been proposed, but agreement on which method better captures the psychosocial work environment has not been reached..$^{57}$ More methodological and theory based work on how to estimate psychosocial work exposures and consensus on analytic issues such as reference group selection is needed. Meanwhile, each method's exposure classification accuracy is unknown and both the quadrants and the quotient methods should be used.

The active learning quotient

A new quotient, the active learning quotient, has been computed for the first time. To date, only the computation of the job strain quotient has been reported. A disadvantage of the job strain quotient is the impossibility of looking at passive work conditions found to be equally hazardous to health. $^{31}{ }^{44}$ The new quotient allows the review of both passive and active job exposures. The active learning quotient is a novel way to consider the active learning hypothesis and the potentially hazardous passive work state.

\section{Time dependence effect}

There is an emerging literature on the time dependent nature of work effects and return to work for patients with low back pain. ${ }^{58} 59$ Amick et al discuss in detail the range of time dependent effects for CTS, ${ }^{25}$ suggesting individual, medical, and economic factors are negative predictors of return to work at two months, and organisational and medical factors at six months. Job strain also exhibited a time dependency effect.

The job strain model predicts high strain work causes stress-associated health problems. The significant high strain effect at six months but not two months further supports the time dependency of predictors of return to work suggested by Amick. ${ }^{25}$ The significant active work effect at two months suggests different psychosocial work states may be more or less important at different time points in the return to work

\section{Policy implications}

- Productivity loss associated with not returning to work or not being able to meet work demands should encourage providers and insurers to address the health and productivity importance of a hazardous psychosocial work environment.

- Rehabilitation sciences need to incorporate models of the psychosocial work environment into their rehabilitation process.

- Collaborative workplace and labour market level interventions to help workers return to work should be promoted between clinicians and employers.

process. As Kristensen suggested, remaining out of work could be viewed as a coping behaviour to avoid or reduce stressful working conditions. ${ }^{60}$ Active workers have more control over when and how they do their job (high job control). As a result, they may be more likely to engage in the coping behaviour. Future research would benefit from theoretical and empirical work considering potential multiple links of active and high strain jobs with work role functioning and time dependence of effects.

\section{CONCLUSIONS}

In summary, despite the impact of some clinical and economic variables found in previous analyses, ${ }^{25}$ the findings of this research underline the importance of considering work related psychosocial conditions in explaining a worker's return to work. In most of the efforts to return people to work, nearly all the emphasis is placed on physical accommodations, evaluating the physical capacities of the person and the physical demands of the job, hardly ever considering other work conditions. This study showed some psychosocial work conditions inhibited people from returning to work-something rarely seen as a legitimate avenue for the providers and insurers to address. Clinicians, researchers, and employers should consider a multidimensional and integrative model of successful work role functioning upon return to work. Moreover, because the evidence of the effects of work process changes on the reduction of CTS is very scarce, ${ }^{61}$ these findings point to the opportunity for collaborative workplace level interventions to facilitate workers successfully returning to work.

\section{ACKNOWLEDGEMENTS}

Dr Gimeno was supported by a Fogarty International Center Training grant (grant 3 D43 TW00644). Drs Amick and Ossmann were supported by a CDC/NIOSH grant (grant number 5R01-OH-03523). Dr Amick was also supported by a grant from the Robert Wood Johnson Foundation (grant number RWJ 038151) and Dr Katz by grants from the NIAMS (grant numbers P60 AR 47782 and K24 AR02123) and by a Clinical Science grant from the Arthritis Foundation. We are grateful to Anne Dybala for her help in editing the paper. We appreciate the editor's as well as the reviewer's suggestions for their comments to improve the paper.

\section{Authors' affiliations}

D Gimeno, B C Amick III, J Ossmann, Southwest Center for Occupational and Environmental Health, School of Public Health, University of Texas-Houston Health Science Center, Houston, TX, USA B C Amick III, Texas Program for Society and Health, Rice University, Houston, Texas, USA and Institute for Work and Health, Toronto, Ontario, Canada

R V Habeck, WE Upjohn Institute for Employment Research, Kalamazoo, MI, USA 
J N Katz, Division of Rheumatology, Immunology and Allergy, Departments of Medicine and Orthopaedic Surgery, Brigham and Women's Hospital, Boston, MA, USA

\section{REFERENCES}

1 Patterson JD, Simmons BP. Outcomes assessment in carpal tunnel syndrome. Hand Clin 2002;18:359-63.

2 Katz JN, Simmons B. Carpal tunnel syndrome. New Eng J Med 2002;346:1807-12.

3 National Institute of Neurological Disorders and Stroke. Carpal tunnel syndrome fact sheet. Available at hitp://www.ninds.nih.gov/disorders/ carpal tunnel/detail_carpal_tunnel.htm (accessed 14 July 2005).

4 Keller RB, Soule DN, Mooney NA, et al. Maine Carpal Tunnel Study: small area variations. J Hand Surg [Am] 1998;23A:697-710.

5 Marshall S, Tardif G, Ashworth N. Local corticosteroid injection for carpal tunnel syndrome. The Cochrane Database of Systematic Reviews, 2002, Issue 4. Art No: CD001554, DOI:10.1002/14651858.CD001554.

6 O'Connor D, Marshall S, Massy-Westropp N. Non-surgical treatment (other than steroid injection) for carpal tunnel syndrome. The Cochrane Database of Systematic Reviews, 2003, Issue 1. Art No: CD003219, DOI:10.1002/ 14651858.CD003219.

7 Verdugo RJ, Salinas RS, Castillo J, et al. Surgical versus non-surgical treatment for carpal tunnel syndrome. The Cochrane Database of Systematic Reviews, 2003, Issue 3. Art No: CD001552, DOI:10.1002/ 14651858.CD001552.

8 Atroshi I, Gummesson C, Johnson R, et al. Symptoms, disability, and quality of life in patients with carpal tunnel syndrome. J Hand Surg 1999;24:398-404.

9 Katz JN, Keller RB, Fossel AH, et al. Predictors of return to work following carpal tunnel release. Am J Ind Med 1997;31:85-91

10 Katz JN, Keller RB, Simmons BP, et al. Maine Carpal Tunnel Study: outcomes of operative and non-operative therapy for carpal tunnel syndrome in a community based cohort. J Hand Surg [Am] 1998;23:697-710.

11 Gerristen AAM, Uitdehaag BMJ, van Geldere D, et al. Systematic review of randomized clinical trials of surgical treatment for carpal tunnel syndrome. Br J Surg 2001;88:1285-95.

12 Franklin GM, Fulton-Kehoe D. Outcomes research in Washington State workers' compensation. Am J Ind Med 1996;29:642-8.

13 Atroshi I, Gummersson C, Johnsson R, et al. Prevalence of carpal tunnel syndrome in the general population. JAMA 1999;282:153-8.

14 National Academy of Sciences and Institute of Medicine. Musculoskeletal disorders and the workplace: low back and upper extremities. Washington, DC: National Academy Press, 2001:358-64.

15 Tanaka S, Wild DK, Seligman PJ, et al. Prevalence and work-relatedness of self-reported carpal tunnel syndrome among U.S. workers: analysis of the Occupational Health Supplement data of 1988 National Health Interview Survey, Am J Ind Med 1995;27:451-70.

16 Franche RL, Krause N. Readiness for return to work following injury or illness: conceptualizing the interpersonal impact of health care, workplace, and insurance factors. J Occup Rehabil 2002;12:233-56.

17 Wellman H, Davis L, Punnett L, et al. Work-related carpal tunnel syndrome (WR-CTS) in Massachusetts, 1992-1997: source of WR-CTS, outcomes, and employer intervention practices. Am J Ind Med 2004;45:139-52.

18 Cheadle A, Franklin G, Wolfhagen C, et al. Factors influencing the duration of work-related disability: A population-based study of Washington State Workers' Compensation. Am J Public Health 1994:84:190-6.

19 Feuerstein M, Burrell LM, Miller VI, et al. Clinical management of carpal tunnel syndrome: A 12-year review of outcomes. Am J Ind Med 1999;35:232-45.

20 Feuerstein M, Marshall L, Shaw WS, et al. Multicomponent intervention for work-related upper extremity disorders. J Occup Rehab 2000;10:71-83.

21 Higgs PE, Edwards D, Martin DS, et al. Carpal tunnel surgery outcomes in workers: effect of workers' compensation status. J Hand Surg 1995;20A:354-60.

22 Wiesel SW, Boden SD, Feffer HL. A quality-based protocol for management of musculoskeletal injuries: a ten-year outcome study. Clin Orthop Rel Res 1994;301:164-76.

23 Leclerc A, Franchi P, Cristofari MF, et al. Carpal tunnel syndrome and work organisation in repetitive work: a cross sectional study in France. Study Group on Repetitive Work. Occup Environ Med 1998;55:180-7.

24 Faucett J, Blanc PD, Yelin E. The impact of carpal tunnel syndrome on work status: Implications of job characteristics for staying on the job. J Occup Rehab 2000; 10:55-69.

25 Amick 3rd BC, Habeck RV, Ossmann J, et al. Predictors of successful work role functioning after carpal tunnel release surgery. J Occup Environ Med 2004:46:490-500.

26 Katz JN, Amick 3rd BC, Keller R, et al. Determinants of work absence following surgery for carpal tunnel syndrome. Am J Ind Med 2005;47:120-30.

27 de Lange AH, Taris TW, Kompier MA, et al. "The very best of the millennium": longitudinal research and the demand-control-(support) model. J Occup Health Psychol 2003;8:282-305.

28 Karasek RA. Job demands, job decision latitude, and mental strain: implications for job redesign. Adm Sci Quart 1979:24:285-308.

29 North FN, Syme L, Feeney A, et al. Psychosocial work environment and sickness absence among British civil servants: the Whitehall II study. Am J Public Health 1996;86:332-40.

30 Vahtera J, Kivimäki $M$, Pentti J, et al. Effect of change in the psychosocial work environment on sickness absence: a seven year follow up of initially healthy employees. J Epidemiol Community Health 2000;54:484-93.
31 Gimeno D, Benavides FG, Amick 3rd BC, et al. Psychosocial factors and workrelated sickness absence among permanent and non-permanent employees. $J$ Epidemiol Community Health 2004;58:870-6.

32 Carmona L, Faucett J, Blanc PD, et al. Predictors of rate of return to work after surgery for carpal tunnel syndrome. Arthritis Care Res 1998;11:298-305.

33 Krause N, Dasinger LK, Deegan $\sqcup$, et al. Psychosocial job factors and returnto-work after compensated low back injury: a disability phase-specific analysis. Am J Ind Med 2001:40:374-92.

34 Janssen N, van den Heuvel WP, Beurskens AJ, et al. The Demand-ControlSupport model as a predictor of return to work. Int J Rehabil Res 2003;26:1-9

35 Schultz IZ, Crook J, Meloche GR, et al. Psychosocial factors predictive of occupational low back disability: towards development of a return-to-work model. Pain 2004;107:77-85.

36 Butler RJ, Johnson WG, Baldwin ML. Managing work disability: Why first return to work is not a measure of success. Ind Labor Rel Rev 1995:48:453-69

37 Chang MS, Amick 3rd BC, Watkins MP, et al. Employer, physical therapist and employee outcomes in the management of work-related upper-extremity disorders. J Occup Rehab 2002;12:257-67.

38 Amick 3rd BC, Lerner DJ, Rogers WH, et al. A review of health-related work outcome measures and their uses, and recommended measures. Spine 2000;25:3152-60.

39 Silverstein BA, Stetson DS, Keyserling WM, et al. Work-related musculoskeletal disorders: comparison of data sources for surveillance. Am J Ind Med 1997;31:600-8.

40 Karasek R, Brisson C, Kawakami N, et al. The job content questionnaire (JCQ): an instrument for international comparative assessments of psychosocial job characteristics. J Occup Health Psychol 1998;3:322-55.

41 Amick 3rd BC, Habeck RV, Hunt A, et al. Measuring the impact of organizational behaviors on work disability prevention and management J Occup Rehab 2000;10:21-38.

42 Karasek R, Theorell T. Healthy work. Stress, productivity, and the reconstruction of working life. New York: NY, Basic Books, 1990:31-82.

43 Maxwell S, Delaney H. Bivariate median splits and spurious statistical significance. Psychol Bull 1993;113:181-90.

44 Amick 3rd BC, McDonough $\mathrm{P}$, Chang $\mathrm{H}$, et al. The Relationship between allcause mortality and cumulative working life course psychosocial and physical exposures in the United States labor market from 1968-1992. Psychosomatic Med 2002;64:370-81

45 Landsbergis PA, Schnall PL, Warren K, et al. Association between ambulatory blood pressure and alternative formulations of job strain. Scand J Work Environ Health 1994;20:349-63.

46 Wells KB, Stewart A, Hays RD. The functioning and well-being of depressed patients: Results from the medical outcomes study. JAMA 1989:262:914-19.

47 Loring K, Chastain RL, Ung E, et al. Development and evaluation of a scale to measure perceived self-efficacy in people with arthritis. Arthritis Rheum 1988;32:37-44.

48 Long JS. Regression models for categorical and limited dependent variables. Thousand Oaks, CA: Sage Publications, 1997:114-48.

49 Brant R. Assessing proportionality in proportional odds model for ordinal logistic regression. Biometrics 1990;46:1171-8.

50 Hosmer DW, Lemeshow S. Applied logistic regression, 2nd edn. New York: Wiley, 2000:116-28.

51 McKelvey RD, Zavonia W. A statistical model for the analysis of ordinal level dependent variables. J Math Sociol 1975;4:103-20.

52 StataCorp. Stata Statistical Software: Release 8.0. College Station: TX, Stata Corporation, 2003.

53 Checkoway H, Pearce NE, Crawford-Brown DJ. Research methods in occupational epidemiology, 2nd edn. New York: Oxford University Press, 2004:83-122.

54 Hallqvist J, Diderichsen F, Theorell T, et al. Is the effect of job strain on myocardial infarction risk due to interaction between high psychological demands and low decision latitude? Results from Stockholm Heart Epidemiology Program (SHEEP). Soc Sci Med 1998;46:1405-15.

55 Bosma $\mathrm{H}$, Marmot MG, Hemingway $\mathrm{H}$, et al. Low job control and risk of coronary heart disease in Whitehall II (prospective cohort) study. BMJ 1997;314:558-65.

56 Greiner BA, Ragland DR, Krause N, et al. Objective measurement of occupational stress factors - an example with San Francisco urban transit operators. J Occup Health Psychol 1997:2:325-42.

57 Frese M, Zapf D. Methodological issues in the study of work stress: objective vs subjective measurement of work stress and the question of longitudinal studies. In: Cooper CL, Payne R, eds. Causes, coping and consequences of stress at work. England: John Wiley \& Sons, Ltd, 1988:375-410.

58 Krause N, Ragland DR. Occupational disability due to low back pain: a new interdisciplinary classification based on a phase model of disability. Spine 1994;19:1011-20.

59 Frank JW, Brooker AS, DeMaio SE, et al. Disability resulting from occupational low back pain. Part II: What do we know about secondary prevention? A review of the scientific evidence on prevention after disability begins. Spine 1996;21:2918-29.

60 Kristensen TS. Sickness absence and work strain among Danish slaughterhouse workers-An analysis of absence from work regarded as coping behaviour. Soc Sci Med 1991;32:15-27.

61 Lincoln AE, Vernick JS, Ogaitis S, et al. Interventions for the primary prevention of work-related carpal tunnel syndrome. Am J Prev Med 2000; 18(Suppl 4):37-50. 